\title{
Interrogating the Intersections of Girls and Sex
}

\author{
Hanna Retallack
}

\section{BOOK REVIEW}

Peggy Orenstein. 2016. Girls \& Sex: Navigating the Complicated New Landscape. New York: Harper Collins. 320 pp. \$26.99. ISBN 978-0-0622-0972-6 (hardback); ISBN 978-0-0622-0973-3

In Girls and Sex: Navigating the Complicated New Landscape (2016), New York Times Peggy Orenstein, journalist and bestselling author, outlines an America in which young women, primed to be perfect princesses (as explored in her 2011 book, Cinderella Ate My Daughter: Dispatches from the Front Lines of the New Girlie-Girl Culture), are traversing a new cultural landscape. It is one that renders them tech savvy and privy to a sex-saturated visual economy while simultaneously denying them the right to sexual safety, equality, and pleasure. Drawing on popular writing on teenage sexuality as well as on academic research of scholars of adolescent sexuality along with feminist psychologists, Orenstein's stated objective is to move beyond moral panic-inducing narratives in order to explore girls' relationship with sex. One-on-one interviews were conducted with over 70 young women between the ages of 15 and 20. These interviews serve as the text's hook as Orenstein draws frank insights from these girls on topics including oral sex, labiaplasty, masturbation, orgasms (or lack of), sexual assault, and abstinence. These numerous in-depth interviews are often fascinating and the author's call to parents to rethink the sex-talk with their children can be seen to be necessary. However, the book's strangely postfeminist take on the wider experiences of girls and young women, its failure to interrogate the intersections of identity that differentiate the constructions of and possibilities for girls' sexuality, as well as the author's investment in popularized discourses around sexualization mean that Orenstein misses crucial complications within the very landscape she works to navigate.

Orenstein's book is popular rather than academic. Reading it alongside scholarly studies by researchers such as Deborah Tolman, R. Danielle 
Egan, Sharon Lamb, Louisa Allen, Emma Renold, Jessica Ringrose, Sara McClelland, and Michelle Fine makes it clear that Girls and Sex is hugely influenced by aspects of academic research. But, by academic standards, the book is problematic, particularly in terms of the lack of specifics about the questions asked and how the answers are analyzed. As I will explore further, the book's major problem is with Orenstein's use of easy protectionist narratives of white middle-class girls' sexuality. However, combine the book's direct appeal to concerned parents and the affectively weighty title and it is easy to see why Girls and Sex garners so much attention.

Orenstein's thesis is that adolescents face obstacles to "full healthy sexual expression" (233). Throughout the course of the seven chapters, these obstacles are identified as pornography, the lack of quality sex-education, selfobjectification, patriarchal purity myths, binge-drinking, the hook-up culture, and an epidemic of sexual assault in universities and high schools. Orenstein's sample of interviewees, sourced from the "daughters of friends of friends" (4) as well as recruited through email blasts to universities, are either at college or high school and, as Orenstein admits, are mostly white, upper middle-class and heterosexual.

Orenstein states that girls were "hungry to talk" (4, emphasis in original). They speak candidly about their negative sexual experiences. Erin, a high school senior discusses her disgust at her own body. She says, "I don't like my vagina" (63). Anna reflects on unreciprocated oral sex and orgasms and exclaims, "It's just expected that the guy will get off" (58). Holly talks about the alcohol-fueled casual sex in the fraternity culture of US campuses and says that "being sober makes it seem like you want to be in a relationship" (119) while Maddie explains her initial decision not to report having been raped because "it's not like he took me to a dark alley" (192). Orenstein's interviewees also report how and where they find pleasure: Brooke recollects her mother giving her sex-positive books to encourage her to know her body; Caitlin remembers her mother buying her a vibrator at 15 (79); and a number of girls describe their first orgasm as "transformative" and "life changing" (129). However, much of what the girls disclose is heart-wrenching and shocking. Many of Orenstein's conclusions, while not necessarily original, are hugely welcome because of the popular attention her work generates, particularly her call for girls to be taught about their bodies (she notes that the notion of a psychological clitoridectomy is a helpful way to outline the silence around the clitoris), feel free to masturbate, feel entitled to sexual pleasure, and question popular constructions of virginity. The potential radicalness of these calls are, however, tempered by a much more conservative 
and protectionist discourse conveyed in Orenstein's key question: How can we protect our girls from risk? As the question suggests, Orenstein appeals to parents who are worrying about their daughters and sex. And it is parents to whom this book is aimed. From the outset, Orenstein includes this assumed parent-reader as an ally in her own concerns for her growing daughter and, throughout the text, positions herself firmly as a mother trying to overcome her own discomfort about the future sex life of those she thinks of as our girls. We are also left to assume that, rather like most of the girls she interviews, these are mostly white middle-class parents who, like Orenstein, cringe at the idea of talking to their kids about sex and who need encouragement from a familiar but much more informed parent. In a surprising aside, Orenstein says that the idea of her child becoming sexually active is "mortifying" (208). After inciting fear by describing the pervasiveness of binge drinking, casual hook-ups, sexting, and assault, Orenstein then quells her readers' anxieties with thought-provoking albeit rather vague observations. Lines such as "whether you're discussing dress codes, social media or the influence of pop culture, there is rarely a clear cut truth" (24) open the door to a developed analysis but never quite make it through. The text concludes with a direct appeal to these parents who want their daughters to have experiences that are "safe, mutual and respectful" (236), arriving at a relevant but rather understated conclusion that if we want girls to achieve the same equality in their intimate lives that they have in the rest of their lives, parents must talk to their girls differently about sex.

The book is founded on a surprisingly postfeminist thesis that holds that girls and women have made it everywhere except in their sexual lives. Orenstein positions girls' sexuality within a schizoid landscape as she observes girls' expectations of egalitarianism in the workplace, and draws on the narratives of successful girls that position them as "winning" because they are succeeding in education and "outnumber boys at college" (3). This premise that girls have made so many gains outside of the bedroom but so few within it suggests clearly that girls' intimate experiences are separate from wider societal inequities. Scholars including Deborah Tolman (2009) have long linked the suppression of female sexuality to the wider patriarchal oppression of women. By ignoring these connections, Orenstein fails to recognize the ways in which sexuality is intertwined with other aspects of life and fails to address the ways in which an experience of sexual pleasure or autonomy (or its lack) is entangled with structures of power.

Orenstein's lack of interrogation of the relations between sex and wider dominant structures is echoed in her decision not to disclose the intersec- 
tions of her interviewees' identities. While there is mention that the sampling net was cast broadly, race, class, and bodily ability are removed entirely from all analysis. Queer identities are confined to one short chapter and girls of color, girls with disabilities, poor girls, and those who sit at the intersections of a few or all of these identities are othered out of Orenstein's analysis so that white, able-bodied, heterosexual girls are the assumed norm. Feminist research into teenage girls' sexuality has widely critiqued social assumptions that girls of color and girls in poverty (see Tolman 2009) are assumed to be hyper- or over-sexual, while black and Latina girls in particular must counteract stereotypes that present them as "vixens or ho's" (Sharpley-Whiting 2007 cited in Lamb 2010: 300), their sexuality constructed in opposition to the fragility of a white, heterosexual, middle class femininity that requires protection. As Lamb (2010) argues, this construction of White girls as vulnerable to victimization and black girls as sexually agentic and invulnerable means that pleasure, desire, and constitutions of healthy sexuality work very differently depending on these intersections of identity. In Orenstein's text, however, the ways in which sexuality is constructed across varied identities goes uninterrogated. Whiteness is assumed and therefore Orenstein's protectionist angle is played out across what appears to be a mass of prematurely sexualized and vulnerable white bodies.

In the West, debates over girls' sexualization have fueled moral outcries in which adult-focused agendas have not taken girls' perspectives into account (Ringrose et al. 2013). Whilst Orenstein's text is centered on the voices of girls and makes claims to move beyond media panics, the discourse remains one of ubiquitous hypersexualization. A fissure is made between "learning to be sexually desirable" (as represented in selfie culture) and "exploring [one's] own desire" (43) that falls into easy subject/object positions (or what Orenstein terms subject/product) that present only two ways of being sexual. Girls who may enjoy feeling desired are placed in a diminished object position (see Lamb 2010) while the subject position that girls are encouraged to take up is murkier, defined only through references to "fullness" and "health" (233). It is unfortunate that in a book so rich with girls' voices, we find such a familiarly adult dominant view of vulnerability and risk.

In the final pages, Orenstein aims a string of rhetorical questions directly at the reader including "Would you like your teenager to explore and understand her own body thoroughly before plunging ahead with partnered sex?" and "Would you hope she can find caring, reciprocal, egalitarian relationships where she can express her needs and limits?" (236). One can almost hear the parents cry, "Of course!" Orenstein's calls for girls to have better 
sex, to know and feel good about their bodies, to demand McClelland's (2010) call for the "intimate justice" mentioned in the title of her article are undeniably right and important. It is, however, one of her final questions, "Would you like her to have fewer partners?" (Orenstein 2016: 236) (with the presumed answer being that yes, they would) that reminds one of the limitations of this book and one begins to wish that another question might be asked. What if these parents were encouraged to engage with their daughters in critical thinking about the very discourses on which Orenstein draws? These are the discourses of whiteness, heteronormativity, slut/whore binaries, achievement, and risk that do not just represent girls' sexuality but produce it. Perhaps then the conversation might be forced to move on from the adult fascination with protecting the sexualized girl-object and we might see how girls themselves navigate their own way through the ever-changing landscape of sex. Just last week, in the high school where I teach, a male teacher told a group of girls that their clothes encouraged their bodies to be "prematurely sexualized" and a female student responded, "Isn't it patronizing to suggest that we aren't sexual beings in our own right?" It is clear that girls are already recognizing the over-emphasis on adults' interpretations of their innocence or corruption and it is the questions of the girls themselves that require a further and truly intersectional interrogation.

Hanna Retallack is a PhD candidate at UCL Institute of Education and teaches at a London Secondary school. E-mail: hanna.retallack.14@ucl.ac.uk

\section{References}

Lamb, Sharon. 2010. "Feminist Ideals for a Healthy Female Adolescent Sexuality: A Critique." Sex Roles 62 (5-6): 294-306.

McClelland, Sara I. 2010. "Intimate Justice: A Critical Analysis of Sexual Satisfaction." Social and Personality Psychology Compass 4 (9): 663-680.

Orenstein, Peggy. Cinderella Ate my Daughter: Dispatches from the Front Lines of the New Girlie-Girl Culture. New York. Harper/HarperCollins Publishers.

Ringrose, Jessica, Laura Harvey, Rosalind Gill, and Sonia Livingstone. 2013.

"Teen Girls, Sexual Double Standards and 'Sexting': Gendered Value in Digital Image Exchange.” Feminist Theory 14 (3): 305-323.

Tolman, Deborah L. 2009. Dilemmas of Desire: Teenage Girls Talk about Sexuality. Cambridge, MA: Harvard University Press. 